European

Thyroid Journal
Eur Thyroid J 2018;7:201-204

DOI: $10.1159 / 000490143$
Received: April 12, 2018

Accepted after revision: May 15, 2018

Published online: July 10, 2018

\title{
The Krakow Declaration on lodine: Tasks and Responsibilities for Prevention Programs Targeting lodine Deficiency Disorders
}

\author{
The EUthyroid Consortium*
}

\section{Keywords}

lodine - lodine deficiency - Neurocognitive function .

Prevention - Epidemiology - Outcomes research .

Harmonization · Multi-stakeholder approach

\begin{abstract}
On April 18, 2018 the EUthyroid consortium released the Krakow Declaration on lodine in response to the increasing concern about the deteriorating commitment of policymakers to address public health strategies against iodine deficiency disorders (IDD) in the European populations. Regulators and policymakers should harmonize obligatory Universal Salt lodization to ensure free trade of fortified foodstuffs in Europe. Similarly, iodized animal feed requires regulatory approval to ensure free trade within the EU. National governments and public health authorities have to perform harmonized monitoring and evaluation of fortification programs at regular intervals to ensure optimal iodine supply to the population. Scientists, together with public health care workers, patient organizations, industry, and the public should support measures necessary to ensure that IDD prevention programs are sustainable, as appropriate within a rapidly changing en-
\end{abstract}

\section{KARGER}

(C) 2018 European Thyroid Association

Published by S. Karger AG, Basel

E-Mail karger@karger.com

www.karger.com/etj vironment and further social awareness of the issue. The declaration defines measures and responsibilities to optimize IDD prevention.

(c) 2018 European Thyroid Association Published by S. Karger AG, Basel

\section{Joint Declaration}

Iodine deficiency disorders (IDD) represent a global health threat to individuals and societies. The adverse effects of iodine deficiency are diverse and impose a significant burden on public healthcare systems. Although this fact is well established, IDD prevention programs receive surprisingly little attention from policy makers, opinion leaders and the public. European epidemiologists, endocrinologists and nutritionists investigating IDD under the umbrella of the Horizon2020 research and innovation action EUthyroid (Project ID: 634453, http:// euthyroid.eu/) are increasingly concerned about the de-

* Members are listed in the appendix. 
teriorating commitment of policymakers to address public health strategies against IDD in the European populations.

\section{Background}

With very few exceptions such as Iceland, Europe is an iodinedeficient continent. Adults living in iodine-deficient regions carry a high risk of goiter, thyroid nodules and hyperthyroidism. Subclinical hyperthyroidism, as a common and frequently undiagnosed IDD, is tightly associated with an increased risk of mortality and coronary heart disease. Moreover, iodine deficiency during pregnancy and breast-feeding is widespread in Europe and adversely affects the development of the child. Even mild or moderate iodine deficiency of the mother affects the synthesis of thyroid hormones and may impair brain development, neurocognitive function and reduces offspring IQ. During pregnancy, women have a sharply increased need for iodine, which is frequently not covered by food sources and iodine supplements. Due to a lack of valid data, we are uncertain about the scale of the problem but estimates suggest that up to $50 \%$ of newborns in Europe are at risk of iodine deficiency.

Iodine deficiency can readily and inexpensively be prevented by iodine fortification, usually by provision of iodized salt. More specifically, iodized salt should replace non-iodized salt in nearly all food production, at least in areas where fortification would not increase risk of excessive iodine intake. This approach will not increase total salt intake, which is in line with current dietary recommendations. However, challenges in implementation remain, particularly in Europe due to fragmentation and a diversity of approaches. The EUthyroid consortium has been collecting experience on national IDD prevention programs. The Krakow Declaration on Iodine aims to define the most important tasks for optimal IDD prevention when programs have been introduced and to point out the responsibilities for the different tasks.

\section{Ensuring a Euthyroid Europe}

We, the signatories of the Krakow Declaration on Iodine call on policymakers, public health officials, scientists and the public to join forces to ensure that existing strategies to prevent IDD are implemented across Europe to reach and secure a sufficient iodine status across Europe. In particular we call for:

- Methods of IDD Prevention: Regulators and policymakers should harmonize obligatory Universal Salt Iodization to ensure free trade of fortified foodstuffs in Europe. Similarly, iodized animal feed requires regulatory approval to ensure free trade within the EU.

- Control of IDD Prevention: National governments and public health authorities have to perform harmonized monitoring and evaluation of fortification programs at regular intervals to ensure optimal iodine supply to the population.
- Support for IDD Prevention: Scientists, together with public-health care workers, patient organizations, industry and the public, should support measures necessary to ensure that IDD prevention programs are sustainable, as appropriate within a rapidly changing environment and further social awareness of the issue.

\section{Methods of IDD Prevention}

\section{Universal Salt Iodization}

Universal salt iodization is the preferred strategy of IDD prevention and is recommended by WHO, UNICEF and the Iodine Global Network as the most cost-effective method. The promotion of universal iodization of salt is not antagonistic to policies aimed at limiting salt uptake to reduce hypertension as a risk factor for cardiovascular disease. Limiting daily salt uptake to less than 5 grams and ensuring iodine sufficiency with fortified salt can be pursued in synergy to ensure optimal implementation and promotion of good health.

- Responsibility for regulation and execution: Governments and public health authorities

- Responsibility for production and quality control: The food industry

\section{Obligatory Principle}

Although grade-A scientific evidence is missing, obligatory prevention programmes by universal salt iodization are preferred over voluntary programs for better control, higher effectiveness and lower costs.

- Responsibility for decisions: Governments and public health authorities.

- Responsibility for providing evidence: Scientists.

\section{Dosage of Iodine Fortification}

The optimal dosage of iodine for fortifying salt needs to be based on up-to-date results of monitoring and evaluation studies.

- Responsibility for decisions: Governments and public health authorities.

- Responsibility for providing valid findings: Scientists.

\section{Transnational Harmonization}

Within a globalized economy with extensive trade of food stuffs across borders, harmonization of national IDD prevention programs is an important priority within the EU to support free movement of goods. Currently, the EU constitutes a fragmented market with different national regulations pertaining to carriers of iodine (potassium iodide or iodate) and methods of IDD prevention (mandatory or voluntary programs). This encourages the food industry to provide non-iodized products to avoid trade barriers. With the exception of Iceland, all salt marketed or used in the EU member and candidate member states for alimentary purposes should be fortified by a universally set minimum amount of iodine. Adopting an agreed universal minimum concentration of salt iodine will allow the safe and effective improvement in the consumption of iodine throughout the EU. Individual member states would be allowed to regulate salt iodine content depending on the severity of iodine deficiency in their geographical regions, 
provided that the locally required salt iodine content is equal to or is higher than universally set minimum amount of iodine.

- Responsibility for decisions: National and EU trade and public health authorities

\section{Control of the IDD Prevention Program}

\section{Monitoring Iodine Status}

IDD programs are embedded within a rapidly changing environment of eating habits, food products and regulatory frameworks. The iodine status of populations can be affected by many factors including changing food patterns, level of iodized salt in foods, differing effectiveness of information campaigns or law amendments. There is a requirement for regular monitoring studies that have to be representative of the target population and must provide valid results.

- Responsibility for initiating and funding the monitoring: Governments and public health authorities.

- Responsibility for providing valid findings: Scientists.

\section{Evaluation}

Monitoring cannot replace the evaluation of IDD prevention programs that are based on observing primary outcomes of the prevention strategy including any trend in incident thyroid diseases and related treatments. Adequate data sources have to be provided for analyses of effectiveness and the monitoring of potential harms.

- Responsibility for regulation and funding: Governments and public health authorities.

- Responsibility for providing adequate data: Public registries, health insurance companies, hospitals, pharmacies and so on.

- Responsibility for providing valid findings: Scientists.

\section{Standardization and Harmonization}

Scientists have to be aware of potential bias in their studies. Monitoring and outcome studies must be standardized to ensure valid data for evidence-based policy decisions. Data should be harmonized as far as possible to enhance the trans-national comparability between different IDD prevention programs and to identify benchmark countries.

- Responsibility: Scientists, data provider for outcome studies.

\section{Measures Accompanying the IDD Prevention Program}

\section{Advisory Boards}

Structures are needed to support governments and public health authorities in accepting responsibility and fulfilling their tasks. Advisory boards should comprise major stakeholders in the field of IDD prevention including thyroidologists, epidemiologists, health economists, pediatricians, gynecologists, nutritionists, communication scientists, patient organizations, representatives of industry and consumer groups.

- Responsibility for initiating and funding: Governments, public health authorities.

Krakow Iodine Declaration of the

EUthyroid Consortium
Information Campaigns

IDD prevention programs, especially those that are voluntary, must be accompanied by public-information campaigns.

- Responsibility for initiating and conducting: Governments, public health authorities.

- Responsibility for advising governments and public health authorities and providing facts and information: Scientists, nutritionists, medical practitioners, patient organizations and industry.

\section{Support us}

We, the signatories of the Krakow Declaration on Iodine ask for support from all stakeholders across Europe and beyond to pool resources and expertise to ensure that our future generations will be able to realize their full potential without any limitation resulting from exposure to iodine deficiency.

The Krakow Declaration on Iodine can be signed via https:// www.iodinedeclaration.eu/.

\section{Acknowledgement}

EUthyroid has received funding from the European Union's Horizon 2020 research and innovation program under grant agreement number 634453 .

\section{Disclosure Statement}

There are no conflicts of interest.

\section{Appendix}

* The EUthyroid Consortium

Steering Committee

Henry Völzke, Universitätsmedizin Greifswald, Germany (Coordinator); Iris Erlund, Terveyden ja hyvinvoinnin laitos, Finland; Iris Grünert, Biolution $\mathrm{GmbH}$, Austria; Alicja HubalewskaDydejczyk, Uniwersytet Jagiellonski Krakow, Poland; John H Lazarus, Iodine Global Network, Canada; Robin P Peeters, Erasmus Universitair Medisch Centrum Rotterdam, the Netherlands; Margaret P Rayman, University of Surrey, United Kingdom; Uwe Siebert, UMIT- Private Universität für Gesundheitswissenschaften, Medizinische Informatik und Technik GmbH; Austria; Betina H Thuesen, Region Hovedstaden, Denmark; Michael B Zimmermann, Eidgenössische Technische Hochschule Zürich, Switzerland

\section{Members (alphabetical order)}

Diana Albrecht, Universitätsmedizin Greifswald, Germany; Petra Arohonka, Terveyden ja hyvinvoinnin laitos, Finland; Sarah C Bath, University of Surrey, United Kingdom; Radovan Bilek, Endokrinologicky Ustav, Czech Republic; Philippe Caron, Centre Hospitalier Universitaire de Toulouse, France; Lisbeth Dahl, Institute of Marine Research, Norway; Joao J de Castro, Ministerio da Defesa Nacional, Portugal; Caterina Di Cosmo, Università di Pisa, Italy, Mariana Dineva, University of Surrey, United Kingdom; Helena Filipsson Nyström, Department of En- 
docrinology, Sahlgrenska University Hospital, and Institute of Medicine, Sahlgrenska Academy, University of Gothenburg, Göteborg, Sweden; Simona Gaberšček, Univerzitetni klinični center Ljubljana, Slovenia; Mehari Gebre-Medhin, Uppsala Universitet, Sweden; Stefan Grünert, Biolution $\mathrm{GmbH}$, Austria; Mònica Guxens, Barcelona Institute for Global Health, Spain; Ingibjorg Gunnarsdottir, Landspitali University Hospital and University of Iceland, Iceland; Sandra Hunziker, Eidgenössische Technische Hochschule Zürich, Switzerland; Till Ittermann, Universitätsmedizin Greifswald, Germany; Ludmila Ivanova, Sofiiski Universitet Sveti Kliment Ohridski, Bulgaria; Tomislav Jukić, Sestre Milosrdnice University Hospital Centre, Zagreb, Croatia; Borislav Karanfilski, Centre for Regional Policy Research and Cooperation Studiorum, Macedonia; Afitap Derya Köprülü, Biolution GMBH, Austria; Tim Korevaar, Erasmus Universitair Medisch Centrum Rotterdam, the Netherlands; Eftychia G Koukkou, University of Patras, Greece; Zvonko Kusić, Croatian Academy of Sciences and Arts, Zagreb, Croatia; Deborah Levie, Fundacion Privada Instituto De Salud Global Barcelona, Spain; Mafalda Marcelino, Ministerio Da Defesa Na- cional, Portugal; Kostas B Markou, University Of Patras, Greece; Neda Milevska, Centre For Regional Policy Research And Cooperation Studiorum, Macedonia; Rodrigo Moreno-Reyes, Université Libre De Bruxelles, Belgium; Endre V Nagy, Debreceni Egyetem, Hungary; Valdis Pīrāgs, Latvijas Universitāte, Latvia; Toomas Podar, OÜ Endokrinoloogiakeskus, Estonia; Manel Puig-Domingo, Institut d'Investigacio en Ciencies de la Salut Germans Trias i Pujol, Spain; Ursula Rochau, UMIT- Private Universität für Gesundheitswissenschaften, Medizinische Informatik und Technik GmbH; Austria; Monika Schaffner, UMITPrivate Universität für Gesundheitswissenschaften, Medizinische Informatik und Technik GmbH; Austria; Matthew WB Spencer, Biolution GmbH, Austria; Ieva Strēle, Latvijas Universitāte, Latvia; Aron M Troen, The Hebrew University Of Jerusalem, Israel; Malgorzata Trofimiuk-Muldner, Uniwersytet Jagiellonski, Poland; Lluis Vila, Hospital de San Joan Despí Moisès Broggi, Spain; Paolo Vitti, Università di Pisa di Pisa, Italy; Benjamin Winter, Universitätsmedizin Greifswald, Germany; Jayne V Woodside, Queen's University Belfast, UK; Vaclav Zamrazil, Endokrinologicky Ustav, Czech Republic 